\title{
Optimizing the Anatomic Reduction of Complex Acetabular Frac- tures: A Technical Enhancement to the Modified Stoppa Approach
}

\section{J Diranzo García*, L Hernández Ferrando, V Estrems Díaz, V Zarzuela Sánchez, L Castillo Ruipérez, A Vilatela Gómez and A Bru Pomer}

Unidad de Cadera y Pelvis, Hospital General universitario Valencia, Spain.

*Corresponding author: J Diranzo García, Hospital General Universitario Valencia, Spain

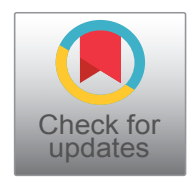

\begin{abstract}
In spite of the large variety of different techniques available for their treatment, acetabular fractures still pose a formidable challenge to the orthopedic surgeon, with a close relationship having been observed between degree of reduction, radiological findings and clinical results. The purpose of this manuscript is to introduce a technical enhancement that can be resorted to following exposure of the acetabular dome when using a modified Stoppa approach to facilitate reduction of bone fragments, a potential bone grafting procedure and the restoration of joint congruity.
\end{abstract}

\section{Introduction}

The Stoppa surgical access was first reported in 1989 for the treatment of inguinal hernia using a pre-peritoneal mesh [1]. The approach was subsequently modified by Hirvensalo, et al. [2] and later by Cole and Bolhofner [3], who turned it into an alternative to the traditional ilioinguinal approach proposed by Judet and Letournel [4-6] for treating the majority of acetabular fractures (anterior column, anterior wall, anterior column with a posterior hemitransverse component, T-shaped and some fractures involving both columns). The Stoppa approach consists of an intrapelvic extraperitoneal approach that allows direct visualization, reduction and fixation of the quadrilateral plate, thereby providing a degree of primary mechanical stability that can seldom be achieved with an ilioinguinal approach [7-12]. This paper describes a technical modification for cases of complex acetabular fractures exhibiting impaction or comminution of the acetabular dome, which can facilitate fracture reduction and subsequent fixation, as well as, if necessary, a potential bone grafting procedure.

\section{Technique}

With the hip in $30-45^{\circ}$ of flexion and the surgeon sitting on the contralateral side of the lesion, an 8-10-centimeter-long horizontal incision is made two centimeters above the pubic symphysis. The linea alba is opened in a craniocaudal direction and the rectus femoris on the same side of the fracture is subperiosteally detached, exposing the pubic symphysis and the superior pubic ramus. Subsequently, the Retzius space can be accessed after reflecting the bladder to protect it from injury. From 4 to $9 \mathrm{~cm}$ lateral to the pubic symphysis, $50-84 \%$ of patients present with a so-called corona mortis [1315], a vascular anastomosis between the obturator and the external iliac artery (Figure 1). This structure must be either ligated or electrocoagulated as it is a potentially dangerous source of bleeding.

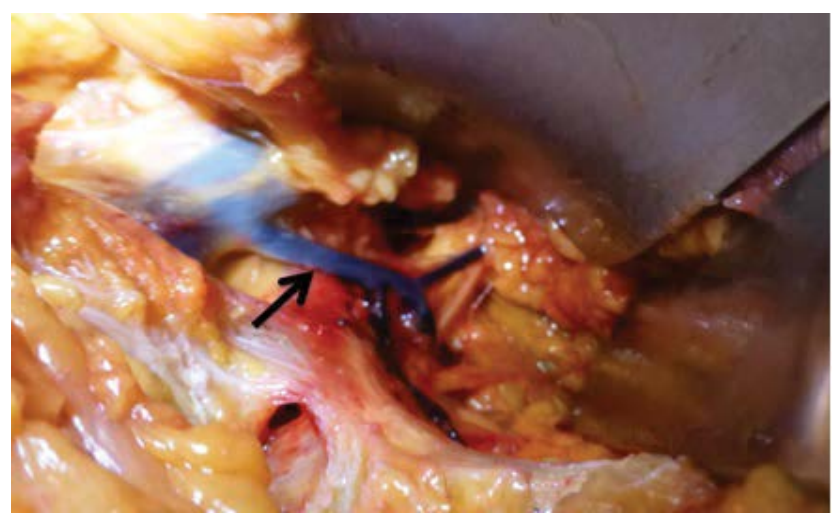

Figure 1: Cadaveric image: Corona Mortis (arrow).

Citation: J Diranzo-García, L Hernandez-Ferrando, V Estrems-Diaz, L Castillo Ruipererez, et al. (2018) Optimizing the Anatomic Reduction of Complex Acetabular Fractures: A Technical Enhancement to the Modified Stoppa Approach. Int Arch Orthop Surg 1:004.

Accepted: November 10, 2018; Published: November 12, 2018

Copyright: (C) $2018 \mathrm{~J}$ Diranzo-García, et al. This is an open-access article distributed under the terms of the Creative Commons Attribution License, which permits unrestricted use, distribution, and reproduction in any medium, provided the original author and source are credited. 


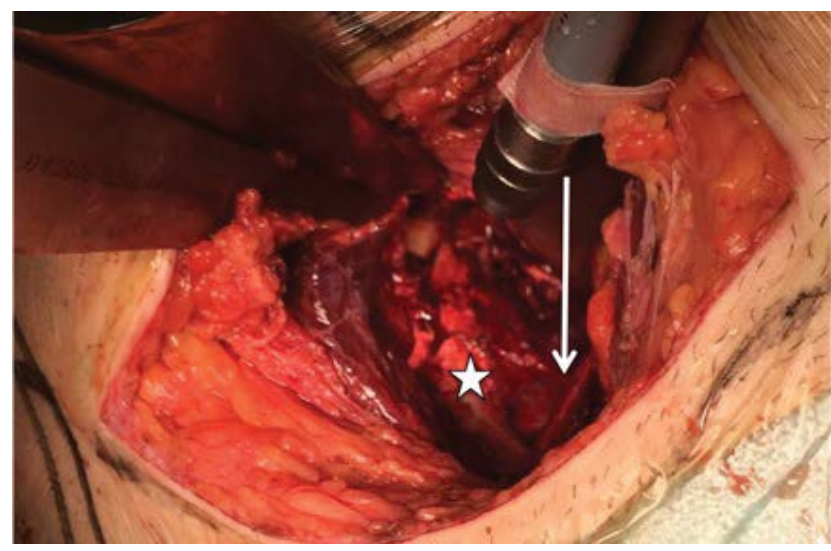

Figure 2: Intraoperative image: exposure of the quadrilateral plate (star) and obturator nerve (arrow).

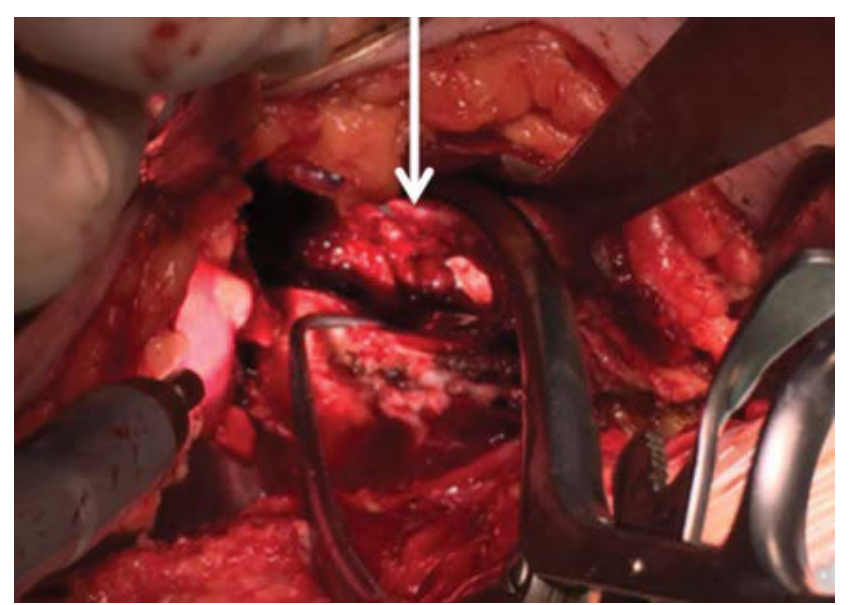

Figure 3: Intraoperative image: bone defect created with the mobilization of the impacted dome (arrow).

The iliopectineal fascia is subsequently detached at the level of the supero-lateral pubic ramus and Hohmann retractors are placed along the anterior col$\mathrm{umn}$, at the level of the linea terminalis, from the anterior pubic ramus to the anterior sacroiliac joint. These retractors are aimed at protecting the external iliac vessels, the iliac psoas and the femoral nerve during the procedure. From that moment onwards, the fracture can be exposed in the mid-pelvic area (Figure 2). Lateral to the fracture, the obturator neurovascular bundle follows an oblique path, from superior-posterior to anterior-inferior, before it enters the obturator foramen. The bundle and the bladder must be protected by placing a blunt Hohmann retractor at the level of the greater sciatic notch. Placement of this retractor makes it possible to expose the posterior column up to the anterior sacroiliac joint, which will be the posterior fixation point of the osteosynthesis used. At that moment, full exposure of the fracture will have been achieved. As a technical enhancement, in cases where the dome has been impacted, the fractured quadrilateral plate can be further medialized with the help of a Cobb periosteal elevator. At the same time, lateral traction is applied to the proximal femur using a Schanz screw inserted in the lesser trochanter. This technical maneuver allows

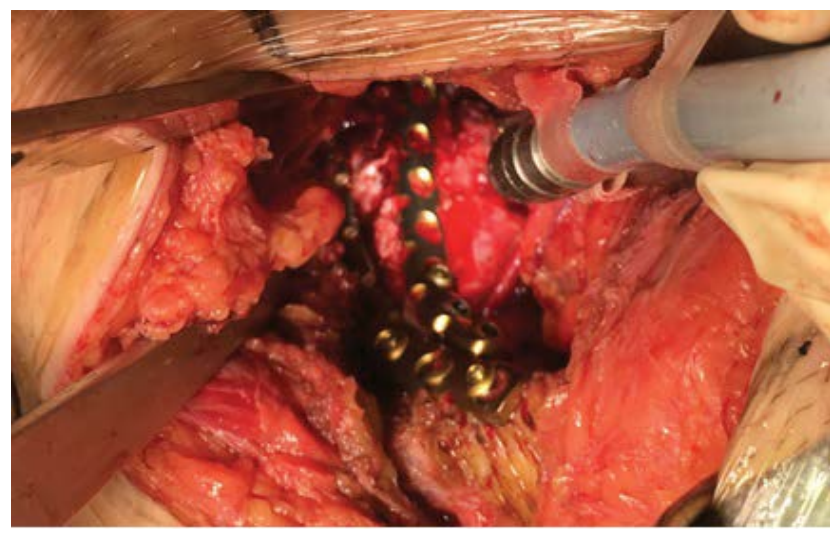

Figure 4: Reduction of the fracture and stabilisation using supra- and infra-pectineal osteosynthesis.

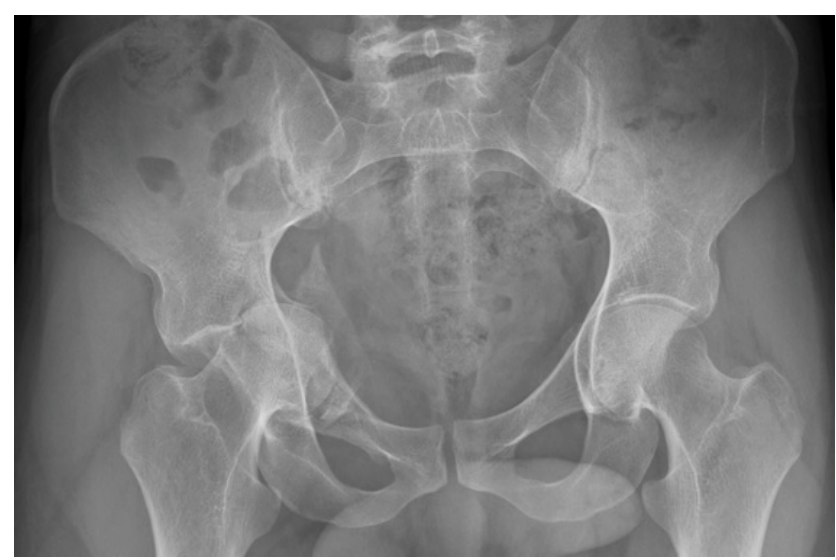

Figure 5: Transverse acetabular fracture in a 24-years-old patient before surgery.

direct visualization of the impacted area. Disimpaction of the dome fracture is performed at the subchondral level, using a $10 \mathrm{~mm}$ scope or a Cobb periosteal elevator. Mobilization of the impacted dome creates a larger bone defect (Figure 3), which requires application of bone grafting to provide robust structural support to the dome area and prevent the dome from shifting back to the original position. We usually use cadaveric bone allograft. The fracture can now be reduced and stabilized by means of an infra-pectineal plate (Figure 4) (3.5 mm Low Profile Pelvic System, Synthes USA, Paoli, PA) supported directly on the quadrilateral plate. The fixation screws must be placed into the two posterior-most screw-holes, located in front of the anterior sacroiliac joint and into the two or three anterior screw-holes, located at iliac-publc level. In Figure 5 and Figure 6, we show a case of a patient with a transverse acetabular fracture before and after being operated by a modified Stoppa approach.

\section{Discussion}

In spite of the development of many new surgical techniques to treat acetabular fractures, such fractures still pose a complex challenge to orthopedic surgeons given the complex anatomy of the acetabular area and the risk of potential complications. The mini-invasive 


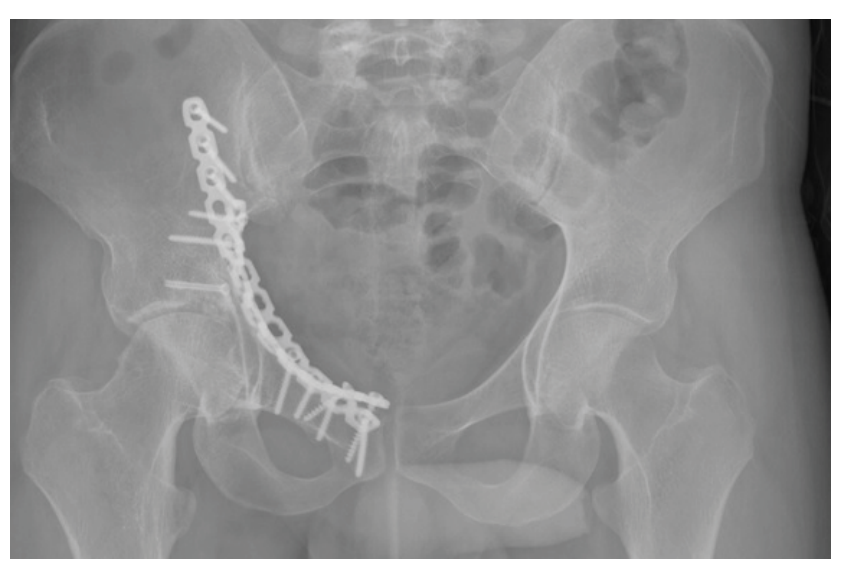

Figure 6: Radiographic control 2 years after the surgery using a modified Stoppa approach.

intrapelvic extraperitoneal modified Stoppa approach allows direct visualization of the medial section of the anterior column, the quadrilateral plate and the medial area of the interior-most portion of the posterior column, $[10,12]$ providing access to the sacroiliac joint, the sciatic spine and the greater and lesser sciatic notches, which allows direct reduction and fixation of most fractures. Earlier studies have shown that the modified Stoppa approach is particularly effective for fractures of the quadrilateral plate with medial displacement and dome impaction [7-12,16,17].

As shown by other authors, [18-20] there exists a close relationship between radiologic and clinical results. Presence of the gull sign, described by Anglen, et al., [21] is indicative of acetabular dome impaction and is often associated to a poor prognosis. Lafflame, et al. [22] correlated comminution of the dome with a less effective reduction and with progression to total hip arthroplasty. In their study, Kim, et al. [18] reported lower reduction rates, and hence poorer functional results, when 3-or-more-part fractures were present in the dome area $(p=0.03)$. For that reason, reconstruction of the acetabular weight bearing area is a prerequisite for satisfactory clinical results. A modified Stoppa approach used in combination with the technical variation proposed in this article could allow reduction of impacted dome fragments and restoration of joint congruity. Subchondral bone grafting can also be used to prevent re-impaction of the fragments, thereby minimizing the negative effects of the presence of dome comminution on clinical patient outcomes.

\section{References}

1. Stoppa RE (1989) The treatment of complicated groin and incisional hernias. World J Surg 13: 545-554.

2. Hirvensalo E, Lindahl J, Kitjunen V (2007) Modified and new approa- ches for pelvic and acetabular surgery. Injury 38: $431-441$

3. Cole JD, Bolhofner BR (1994) Acetabular fracture fixation via a modified Stoppa limited intrapelvic approach: description of operative technique and preliminary treatment results. Clin Orthop Relat Res 305: 112-123.
4. Judet R, Judet J, Letournel E (1964) Fractures of the acetabulum: classification and surgical approaches for open reduction. preliminary report. J Bone Joint Surg 46: 1615-1646.

5. Letournel $E$ (1993) The treatment of acetabular fractures though the ilioinguinal approach. Clin Orthop 292: 62-76.

6. Letournel $E$ (1994) Fractures of the acetabulum. A study of a series of 75 cases. Clin Orthop 305: 5-9.

7. Isaacson MJ, Taylor BC, French BG, Poka A (2014) Treatment of acetabulum fractures through the modified Stoppa ap- proach: strategies and outcomes. Clin Orthop Relat Res 472: 3345-3352.

8. Ma K, Luan F, Wang X, Ao Y, Liang Y, et al. (2013) Randomized, controlled trial of the modified Stoppa versus the ilioinguinal approach for acetabular fractures. Orthopedics 36: 1307-1315.

9. Shazar N, Eshed I, Ackshota N, Hershkovich O, Khazanov A, et al. (2014) Comparison of acetabular fracture reduction quality by the ilioinguinal or the anterior intrapelvic (modified Rives-Stoppa) surgical approaches. J Orthop Trauma 28: 313-319.

10. Keel MJ, Bastian JD, Büchler L, Siebenrock KA (2013) Anterior approaches to the acetabulum. Unfallchirurg 116: 213-220.

11. Taller S, Srám J, Lukás R, Krivohlávek M (2010) Surgical treatment of pelvic ring and acetabular fractures using the Stoppa approach. Acta Chir Orthop Traumatol Cech 77: 9398.

12. Sagi HC, Afsari A, Dziadosz D (2010) The anterior intra-pelvic (modified rives-stoppa) for fixation of acetabular fractures. J Orthop Trauma 24: 263-270.

13. Rusu MC, Cergan R, Motoc AG (2010) Anatomical considerations on the corona mortis. Surg Radiol Anat 32: 17-24.

14. Darmanis S, Lewis A, Mansoor A, Bircher M (2007) Corona mortis: An anatomical study with clinical implications in approaches to the pelvis and acetabulum. Clinical Anatomy 20: 433-439.

15. Okcu G, Erkan S, Yercan HS, Ozic U (2004) The incidence and location of corona mortis: A study on 75 cadavers. Acta Orthop Scand 75: 53-55.

16. Khoury A, Weill Y, Mosheiff R (2012) The Stoppa approach for acetabular fracture. Oper Orthop Traumatol 24: 439448.

17. Verbeek DO, Ponsen KJ, van Heijl M, Goslings JC (2018) Modified Stoppa approach for operative treatment of acetabular fractures: 10-year experience and mid-term follow-up. Injury 49: 1137-1140.

18. Kim HY, Yang DS, Park CK, Choy WS (2015) Modified Stoppa approach for surgical treatment of acetabular fracture. Clin Orthop Surg 7: 29-38.

19. Matta JM, Merritt PO (1988) Displaced acetabular fractures. Clin Orthop Relat Res 230: 83-97.

20. Pantazopoulos T, Mousafiris C (1989) Surgical treatment of central acetabular fractures. Clin Orthop Relat Res 246: 57-64.

21. Anglen JO, Burd TA, Hendricks KJ, Harrison P (2003) The "Gull Sign": a harbinger of failure for internal fixation of geriatric acetabular fractures. J Orthop Trauma 17: 625-634.

22. Laflamme GY, Hebert-Davies J, Rouleau D, Benoit B, Leduc S (2011) Internal fixation of osteopenic acetabular fractures involving the quadrilateral plate. Injury 42: 11301134. 